\title{
Challenges faced by young third-world doctors
}

Alam $M K^{1}$, Arshad $A I^{2}$

International Journal of Human and Health Sciences Vol. 02 No. 03 July'18 Page : 106-106 DOI: http://dx.doi.org/10.31344/ijhhs.v2i3.36

Health care profession is always considered a sensible and prior choice while planning careers, particularly in terms of occupational prestige. Contemporaneously, lamentation is frequently noticed among recent graduates in the third-world countries like Pakistan, Bangladesh, Columbia, Nigeria and Philippines. ${ }^{1}$ According to recent facts from respective medical and dental student governing bodies, in Punjab, Pakistan almost 15 students competed for a single admission slot. ${ }^{2}$ Whereas, in Dhaka, Bangladesh 24 students competed for one slot. ${ }^{3}$

After struggling to secure this slot, striving through the toughest four to five years of professional examinations and completing one year of resident training, the young graduate stands facing a future of utter despair. With the ever growing inflation that has struck these countries, doctors are forced to either work an average of 14-16 hours a day or queue up again for licencing examination and immigration to developed countries. ${ }^{4}$

The level of frustration is relative to an individuals' environment. According to $\mathrm{Wu}$ and colleagues, an element of antagonism against and among young doctors have been reported. ${ }^{5}$ In our case, "aversion" has manifested in the forms of protests, banner raising and long marches. Such behaviours on part of doctors could be attributed to the financial paucity or a matter of prestige. To boil it down, raising the minimum wages, promising incentives, and post-graduate scholarship programs for young doctors could alleviate the situation. We faithfully intend convey this message to the concerned governing bodies for a better and prosperous future.

\section{References:}

1. Astor A, Akhtar T, Matallana MA, et al. Physician migration: views from professionals in Colombia, Nigeria, India, Pakistan and the Philippines. Social science \& medicine 2005; 61(12): 2492-500.

2. Atif M. UHS Fact Book 2015. 2015. http://www.uhs. edu.pk/downloads/factbook.pdf (accessed April 18, 2016).

3. Shohan AA-A. Medical Admission and Dental Admission 2015-16 Statistics. 2015. http:// resultnotice.com/medical-admission-result-2014check-dghs-teletalk-com-bd/ (accessed April 22, 2016).

4. Hashmi AM. Between a rock and a hard place. 2015. http://www.dawn.com/news/1196555/ (accessed April 21, 2016).

5. Wu LX, Qi L, Li Y. Challenges faced by young Chinese doctors. The Lancet 2016; 387(10028): 1617.

1. Mohammad Khursheed Alam, Associate Professor, Orthodontic Department, College of Dentistry, Aljouf University. Sakaka, KSA.

2. Anas Imran ArShAD, School of Dental Sciences, UniversitiSains Malaysia. Kota Bharu, Kelantan, Malaysia.

Correspondence to: Mohammad Khursheed AlAM, ssociate Professor, Orthodontic Department, College of Dentistry, Aljouf University. Sakaka, KSA.e-mail: dralam@gmail.com 